\title{
Prognostic value of copeptin in patients with acute myocardial infarction treated with percutaneous coronary intervention: a prospective cohort study
}

\author{
Marta Roczek-Janowska, Michal Kacprzak, Malgorzata Dzieciol, Marzenna Zielinska, \\ Krzysztof Chizynski \\ Department of Interventional Cardiology, Medical University of Lodz, Lodz, Poland \\ Contributions: (I) Conception and design: K Chizynski; (II) Administrative support: M Zielinska; (III) Provision of study materials or patients: M \\ Zielinska, K Chizynski; (IV) Collection and assembly of data: M Roczek-Janowska, M Dzieciol; (V) Data analysis and interpretation: M Roczek- \\ Janowska, M Kacprzak, M Dzieciol; (VI) Manuscript writing: All authors; (VII) Final approval of manuscript: All authors \\ Correspondence to: Marta Roczek-Janowska, MD. Department of Interventional Cardiology, Medical University of Lodz, Central Clinical Hospital, \\ Pomorska 251, 92213 Lodz, Poland. Email: marta.roczek@gmail.com.
}

Background: Ischemic myocardial injury leads to neurohormonal system activation and increased release
of copeptin. Although diagnostic value of copeptin has been widely described, data on its prognostic
performance in patients with myocardial infarction is inconclusive. The aim of this study was to asses if
elevated copeptin concentration provides prognostic information for long-term adverse cardiac events in a
cohort of first acute myocardial infarction patients treated with percutaneous coronary intervention.
Methods: Copeptin concentration was assessed in a cohort of 100 consecutive patients ( $39 \%$ women; mean
age $63 \pm 7$ years) presenting with first acute myocardial infarction and subjected to percutaneous coronary
intervention. Samples were collected at the time of admission and on the $4^{\text {th }} / 5^{\text {th }}$ day of hospitalisation. All
patients were followed-up prospectively for 12 months for the occurrence of major adverse cardiovascular
events defined as reinfarction, unscheduled coronary revascularisation and all-cause death.
Results: Elevated copeptin concentration on the $4^{\text {th }} / 5^{\text {th }}$ day of hospitalisation was identified as a predictor
of major adverse cardiovascular events $(\mathrm{P}=0.0445)$. The increase between copeptin level on admission and
on day $4^{\text {th }} / 5^{\text {th }}$ was associated with the requirement for unscheduled coronary revascularisation in receiver
operating characteristics $(\mathrm{ROC})$ analysis $(\mathrm{AUC}=0.639 ; 95 \%$ CI: $0.504-0.773$; $\mathrm{P}=0.0430$ ). In a multivariate
analysis, copeptin concentration on the $4^{\text {th }} / 5^{\text {th }}$ day of hospitalisation and left ventricular ejection fraction
assessed by transthoracic echocardiography, were the only predictors for major adverse cardiac events during
follow-up $(\mathrm{P}=0.024$ and $\mathrm{P}=0.001$, respectively).

Conclusions: Copeptin seems to be a prognostic marker in patients with first myocardial infarction treated with percutaneous coronary intervention.

Keywords: acute coronary syndrome, copeptin, myocardial infarction, prognostic value.

Submitted Mar 04, 2021. Accepted for publication May 14, 2021.

doi: $10.21037 /$ jtd-21-359

View this article at: https://dx.doi.org/10.21037/jtd-21-359

\section{Introduction}

Ischemic myocardial injury during acute myocardial infarction (AMI) leads to rapid activation of neurohormonal system including hypothalamic-pituitary-adrenal axis (1). Arginine vasopressin (AVP), a hypothalamic hormone secreted from the posterior pituitary gland in response to hemodynamic and osmotic stimuli, through 3 different receptors regulates plasma osmolality and volemia, mediates vasoconstriction and liver glycogenolysis and stimulates the secretion of adrenocorticotropic hormone mediating 
endocrine stress response (2). Therefore, AVP plays a fundamental role in cardiovascular system regulation. However, AVP usage in clinical routine is limited by its short half-life time, ex vivo instability and time-consuming measurement (3).

Copeptin, a 39-aminoacid glycopeptide, which is the C-terminal part of the AVP precursor, is cosecreted with AVP in equimolar amounts $(4,5)$. Biological significance of copeptin remains unknown, but most probably it is involved in the structural maturation process of AVP (6). Copeptin assay does not require complex preanalytical preparation, the glycopeptide is stable in biological samples and can easily serve as a sensitive marker for AVP activity (7-9).

In the setting of an AMI, copeptin is secreted rapidly after the onset of symptoms and decrease gradually reaching plateau phase on the $3^{\text {rd }}-5^{\text {th }}$ day (10). Several studies reported elevated copeptin values at the time of hospital admission with the highest concentration observed within the first 4 hours after the chest pain onset (10-13). Due to different release kinetics comparing to cardiac troponin (cTn) (13), copeptin was shown to be a complementary diagnostic marker in patients with suspected AMI, serving as a useful tool for rapid rule-out of myocardial infarction (14-17). However, since high-sensitive cardiac troponin (hs-cTn) assays were introduced into clinical practice, diagnostic application of copeptin is being challenged (18-22).

Prognostic value of copeptin in patients with AMI was primarily described by Khan et al. (10). Copeptin was helpful for predicting mortality or re-hospitalisation due to congestive heart failure within 60 days after AMI. Subsequent studies have presented the association between copeptin and the degree of left ventricular dysfunction and remodeling after an acute event (23-25). In the matter of adverse outcome prediction, existing data showed many discrepancies (26-30). The heterogeneity among studies limits the interpretation and comparison of data. The differences between study groups and time points for obtaining blood samples, different copeptin assays and finally various methods of implemented reperfusion therapy, create the area for further evaluation of copeptin as a prognostic marker in accordance to current standards of management in AMI.

The aim of this study was to asses if elevated copeptin concentration was a predictor for long-term adverse cardiac events in a cohort of patients with first acute myocardial infarction treated with percutaneous coronary intervention $(\mathrm{PCI})$.

We present the following article in accordance with the
STROBE reporting checklist (available at https://dx.doi. org/10.21037/jtd-21-359).

\section{Methods}

\section{Study population}

We evaluated 100 consecutive patients admitted to the Department of Interventional Cardiology, Medical University of Lodz between January 2017 and December 2017 with first AMI who required percutaneous coronary intervention as a primary strategy. Exclusion criteria comprised lack of informed consent to participate in the study, end-stage renal failure, neoplasmatic process within last 5 years and ongoing acute infectious disease. The study flowchart is presented on Figure 1.

The study was conducted in accordance with the Declaration of Helsinki (as revised in 2013). The study was approved by the Bioethics Committee at Medical University of Lodz (RNN/217/13/KE) and informed consent was taken from all individual participants.

\section{Study protocol}

All participants underwent coronarography and received PCI within the time frames recommended in the current guidelines for the management of ST-segment elevation myocardial infarction (STEMI) (31) and non-ST-segment elevation myocardial infarction (NSTEMI) (32). Standard pharmacological therapy including aspirin, clopidogrel, beta-blockers, ACE-inhibitors and statins was introduced. Decision to use glycoprotein IIb/IIIa inhibitors was made by an independent physician performing PCI.

Data on clinical characteristic regarding cardiovascular risk factors were obtained on admission. Each patient underwent physical examination, 12-lead electrocardiogram, continuous bedside ECG monitoring for at least 24 hours and standard blood tests. Transthoracic echocardiography was performed before discharge. The left ventricular function was assessed by estimating the left ventricular ejection fraction (LVEF) using the biplane Simpson's method.

All patients were followed-up prospectively for 12 months for the major adverse cardiovascular events (MACE) defined as reinfarction, the need for unscheduled coronary revascularisation procedure (PCI or CABG) or allcause death. The telephone follow-up contact with patients or their close relatives was conducted. No patient was lost to follow-up. 


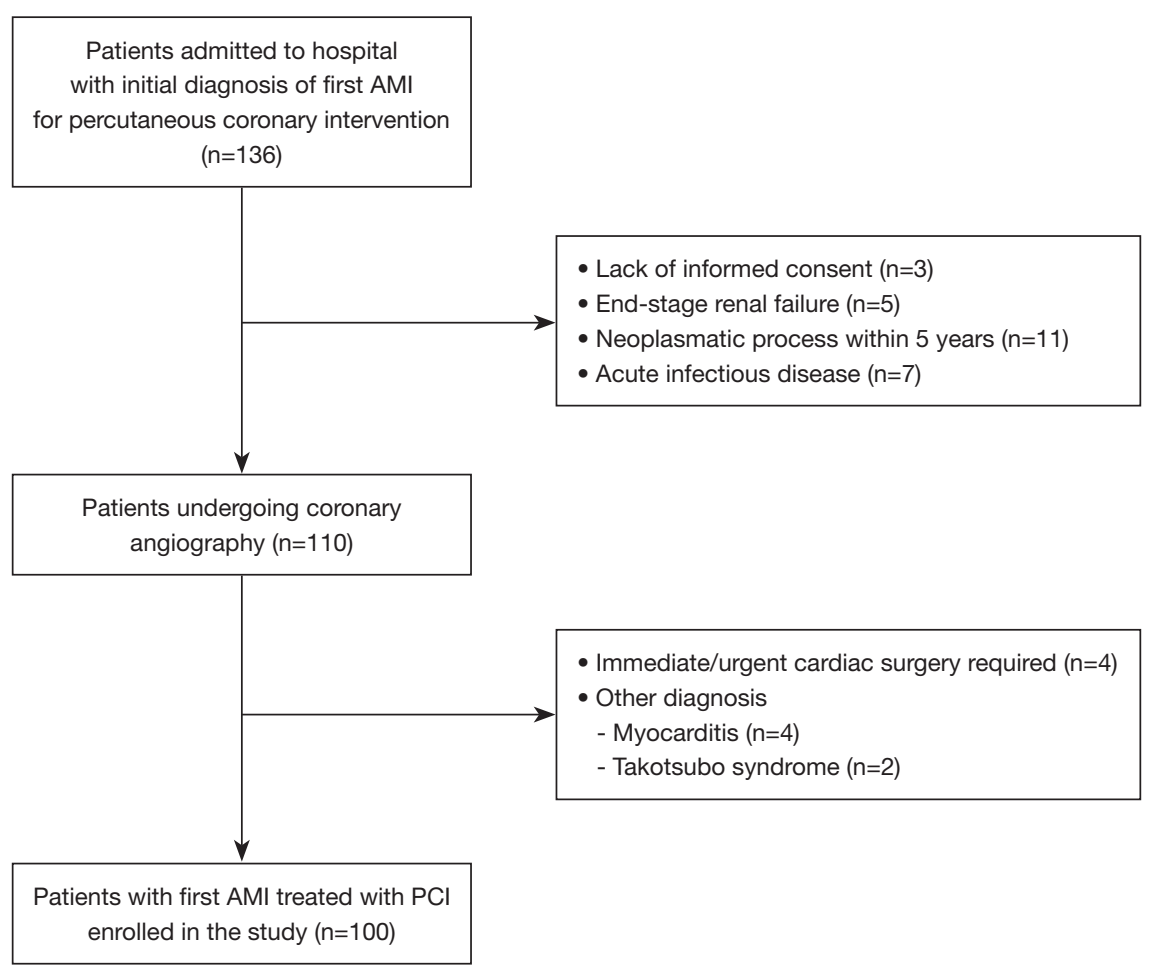

Figure 1 Study flowchart. AMI, acute myocardial infarction; PCI, percutaneous coronary intervention.

\section{Copeptin assay}

Copeptin sampling was carried out on admission (copeptin -1) and on the $4^{\text {th }} / 5^{\text {th }}$ day of hospitalisation (copeptin - 2). Venous blood samples were collected into EDTA tubes and subsequently centrifuged within 30 minutes. Obtained plasma was frozen and stored at $-80{ }^{\circ} \mathrm{C}$ until analysed. Maximal storage period was 2 months and did not exceed the time recommended by the manufacturer. Copeptin concentration was measured using sandwich ELISA (enzyme-linked immunosorbent assay) test with a commercial assay (ELISA kit for copeptin (CPP); USCN Life Science Inc.; Wuhan). The assay measuring range was $15.6-1,000 \mathrm{pg} / \mathrm{mL}$ with the detection limit $6.1 \mathrm{pg} / \mathrm{mL}$.

Other blood tests routinely performed in patients with AMI were conducted, including high sensitive cardiac troponin $\mathrm{T}$ (hs-cTnT). Concentration of C-reactive protein (CRP) and $\mathrm{N}$-terminal prohomone of B-type natriuretic peptide (NT-proBNP) was also determined both on admission and on the $4^{\text {th }} / 5^{\text {th }}$ day of hospitalisation.

\section{Statistical analysis}

Continuous variables were presented as median with an interquartile range (IQR). Categorical variables were summarised with frequencies and percentages. Normal distribution of the variables was assessed using the ShapiroWilk test. Comparison of the variables with other than normal distribution was made with non-parametric statistics. Correlations were determined with the Spearman's rank correlation test. The Mann-Whitney $U$ test and Kruskal-Wallis analysis of variances were used to compare continuous variables.

To assess variables associated with the occurrence of MACE forward stepwise logistic regression was performed. The prognostic value of copeptin was established from receiver operating characteristics (ROC) curve.

Statistical analyses were performed using STATISTICA version 13.0 (STATISTICA, RRID:SCR_014213) and MedCalc version 18.2.1 (MedCalc, RRID:SCR_015044). For all tests, $\mathrm{P}$ values $<0.05$ were regarded statistically significant.

\section{Results}

The mean age in our study population was 63 (range, 5770) years; women constituted $39 \%$ of patients. The diagnosis of STEMI was settled in $84 \%$ of cases. $16 \%$ of patients 
Table 1 Baseline characteristic of patients

\begin{tabular}{|c|c|}
\hline Variable & Total $(n=100)$ \\
\hline Age & $63[57-70]$ \\
\hline Female & 39 \\
\hline STEMI & 84 \\
\hline $\begin{array}{l}\text { Time since onset of symptoms to } \\
\text { reperfusion (hours) }\end{array}$ & $4.5[2-12]$ \\
\hline Systolic blood pressure $(\mathrm{mmHg})$ & $130[115-150]$ \\
\hline \multicolumn{2}{|l|}{ Killip class } \\
\hline 1 & 70 \\
\hline II-IV & 30 \\
\hline Anterior AMI & 37 \\
\hline Serum creatinine ( $\mu \mathrm{mol} / \mathrm{L})$ & 76 [60-91] \\
\hline eGFR (mL/min/1.73 m²) & $88[62-117]$ \\
\hline Time of hospital stay (days) & $6[5-7]$ \\
\hline \multicolumn{2}{|l|}{ Cardiovascular risk factors } \\
\hline Arterial hypertension & 77 \\
\hline Hyperlipidaemia & 57 \\
\hline Diabetes mellitus & 22 \\
\hline Smoking & 64 \\
\hline Family history of CAD & 39 \\
\hline \multicolumn{2}{|l|}{ BMI } \\
\hline$\geq 25.0-29.9 \mathrm{~kg} / \mathrm{m}^{2}$ & 45 \\
\hline$\geq 30 \mathrm{~kg} / \mathrm{m}^{2}$ & 24 \\
\hline \multicolumn{2}{|l|}{ Coronary artery disease } \\
\hline 1 vessel & 45 \\
\hline MVD & 55 \\
\hline Stent implantation & 97 \\
\hline \multicolumn{2}{|l|}{ Medications } \\
\hline Aspirin & 97 \\
\hline Clopidogrel & 100 \\
\hline GP IIb/Illa blocker & 45 \\
\hline B-blockers & 92 \\
\hline ACE-inhibitors & 96 \\
\hline Statins & 100 \\
\hline Diuretics & 55 \\
\hline Inotropic agents & 13 \\
\hline
\end{tabular}

Continuous variables are presented as median (interquartile range); categorical variables are presented as numbers. AMI, acute myocardial infarction; CAD, coronary artery disease; BMI, body mass index; MVD, multi-vessel disease.

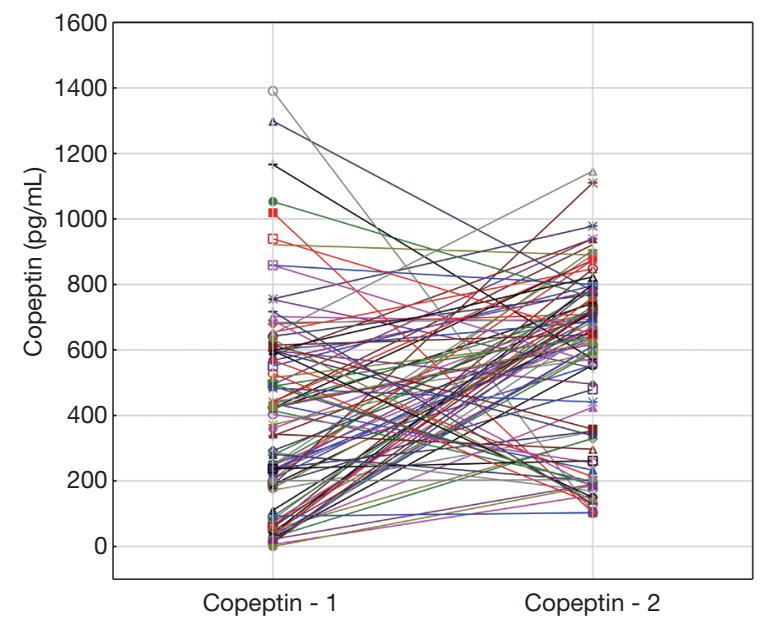

Figure 2 Copeptin concentration on admission to hospital (copeptin - 1) and on $4^{\text {th }} / 5^{\text {th }}$ day of hospitalisation (copeptin - 2) in individual patients.

presented with symptoms of ongoing ischemia and dynamic ST-segment changes in the ECG and therefore required immediate invasive treatment although finally did not meet STEMI criteria. Coronarography was performed in each study participant within 4.5 (range, 2-12) h from symptoms onset; for STEMI patients within 3 (range, $2-10)$ h. Coronary intervention with stent implantation was performed in $97 \%$ of cases (in 3\% of cases stent implantation was technically impossible), $39 \%$ had further percutaneous interventional treatment scheduled and $6 \%$ required surgical revascularisation. Median LVEF was $45 \%$ (range, 40-50\%). In $6 \%$ of patients left ventricular systolic function was preserved (EF $\geq 55 \%$ ), in $72 \%$ of cases it was moderately impaired (EF $\geq 40 \%$ and $<55 \%$ ) and severely impaired (EF $<40 \%)$ in $22 \%$ of patients. The baseline characteristics of study participants are provided in Table 1 .

Copeptin - 1 plasma concentration was 440.95 (range, 250.80-614.40) pg/mL and copeptin - 2 was 647.60 (range, 344.20-760.30) pg/mL $(\mathrm{P}<0.0001)$ (Figure 2). Patients with NSTEMI had significantly higher copeptin levels than patients with STEMI and this association was observed in both time points $(\mathrm{P}=0.0192$ and $\mathrm{P}=0.0084$, respectively). Copeptin concentration did not directly correlate with the time since onset of symptoms $(\mathrm{P}=0.8009)$ but if patients were divided into four groups according to the time of symptoms onset, highest median copeptin level was observed in patients presenting between 3 and 6 hours after the symptoms started (Table 2).

In the study cohort almost all of the classical risk 
Table 2 Copeptin concentration at presentation in relation to symptoms onset

\begin{tabular}{lc}
\hline Symptoms onset & $\begin{array}{c}\text { Median copeptin concentration } \\
(I Q R)(p g / m L)\end{array}$ \\
\hline$<3$ hours $(n=29)$ & $281.50(75.20-568.00)$ \\
$3-6$ hours $(n=28)$ & $465.05(232.75-690.55)$ \\
$>6-12$ hours $(n=22)$ & $394.20(206.40-614.40)$ \\
$>12-24$ hours $(n=21)$ & $251.60(74.60-494.50)$ \\
$P$ & 0.112 \\
\hline
\end{tabular}

factors for CAD did not affected copeptin levels, both on admission and later during hospital stay (Table 3). There was no association between copeptin concentration and sex, age and Killip class. We found that non-smokers had lower copeptin -2 levels $(\mathrm{P}=0.0277)$ and observed a tendency to higher copeptin -1 values in patients without family history of CAD $(\mathrm{P}=0.0507)$. No relation was detected between copeptin -1 concentration and the number of critically obstructed coronary arteries. LV systolic function (considered as preserved, moderately or severely impaired) was not related to copeptin values $(\mathrm{P}=0.628$ and $\mathrm{P}=0.71$ for copeptin -1 and copeptin -2 , respectively) (Figure 3), there was also no direct correlation between EF and copeptin concentration $(\mathrm{P}=0.428$ and $\mathrm{P}=0.306$ for copeptin -1 and copeptin -2 , respectively). Copeptin did not correlated with systolic blood pressure on admission $(\mathrm{r}=-0.585, \mathrm{P}=0.563)$. There were 13 cases of cardiogenic shock, but patients who required inotropic agents administration were not different in terms of copeptin - 1 and copeptin - 2 concentration ( $\mathrm{P}=0.098$ and $\mathrm{P}=0.264$, respectively).

We did not observe any association between both copeptin levels and hs-TnT, CRP or NT-proBNP concentration.

Developing heart failure symptoms during hospital stay was not related to copeptin -1 concentration. However, we found that patients who experienced atrial fibrillation (AF) episode during hospitalisation had significantly higher levels of copeptin on admission ( $\mathrm{P}=0.0406)$. Average hospitalisation time was $6.85 \pm 3.31$ days. Hospitalisation above 10 days concerned 13 patients and resulted from complications such as cardiogenic shock $(\mathrm{n}=5)$, 3rd degree atrioventricular block $(\mathrm{n}=3)$, mechanical complications of myocardial infarction $(\mathrm{n}=1)$, acute kidney injury $(\mathrm{n}=3)$ and pericarditis $(\mathrm{n}=1)$.

We noted 5 (5\%) in-hospital deaths. There were no differences between patients who died and survivors in terms of copeptin -1 level $(\mathrm{P}=0.1231)$. During the follow-
Table 3 Correlation of copeptin - 1 with clinical and demographical variables

\begin{tabular}{|c|c|c|}
\hline Variables & Copeptin - 1 level, median (IQR) & $P$ value \\
\hline Sex & & 0.843 \\
\hline Male & $415.00(92.00-599.80)$ & \\
\hline Female & $337.30(188.10-568.00$ & \\
\hline AMl type & & 0.019 \\
\hline STEMI & 287.95 (92.30-575.90) & \\
\hline NSTEMI & 495.95 (319.60-754.75) & \\
\hline Killip class & & 0.720 \\
\hline Class I & 348.70 (597.80-505.20) & \\
\hline Class II-IV & 412.65 (205.90-649.80) & \\
\hline \multicolumn{3}{|l|}{ Risk factors } \\
\hline Hypertension & & 0.342 \\
\hline Present & $415.00(187.70-599.80)$ & \\
\hline Absent & $227.50(58.60-515.30)$ & \\
\hline Dyslipidemia & & 0.536 \\
\hline Present & $427.40(92.60-599.80)$ & \\
\hline Absent & $292.50(178.10-515.30)$ & \\
\hline Diabetes & & 0.768 \\
\hline Present & $244.00(92.60-599.80)$ & \\
\hline Absent & 409.05 (171.50-597.80) & \\
\hline Smoking & & 0.846 \\
\hline Present & $351.70(92.30-598.80)$ & \\
\hline Absent & $421.40(187.90-597.80)$ & \\
\hline Family history of CAD & & 0.051 \\
\hline Present & $250.00(45.60-550.90)$ & \\
\hline Absent & 420.60 (205.90-614.40) & \\
\hline BMI & & 0.641 \\
\hline$\geq 30 \mathrm{~kg} / \mathrm{m}^{2}$ & 242.75 (131.45-539.35) & \\
\hline$<30 \mathrm{~kg} / \mathrm{m}^{2}$ & $417.80(141.00-606.10)$ & \\
\hline Coronary angiogram & & 0.753 \\
\hline Single vessel disease & 419.35 (174.80-597.80) & \\
\hline Multi-vessel disease & $280.30(101.55-590.80)$ & \\
\hline Cardiogenic shock & & 0.098 \\
\hline Yes & 499.25 (205.90-653.90) & \\
\hline No & $314.90(92.60-597.80)$ & \\
\hline
\end{tabular}

IQR, interquartile range; AMI, acute myocardial infarction; CAD, coronary artery disease; BMI, body mass index. 

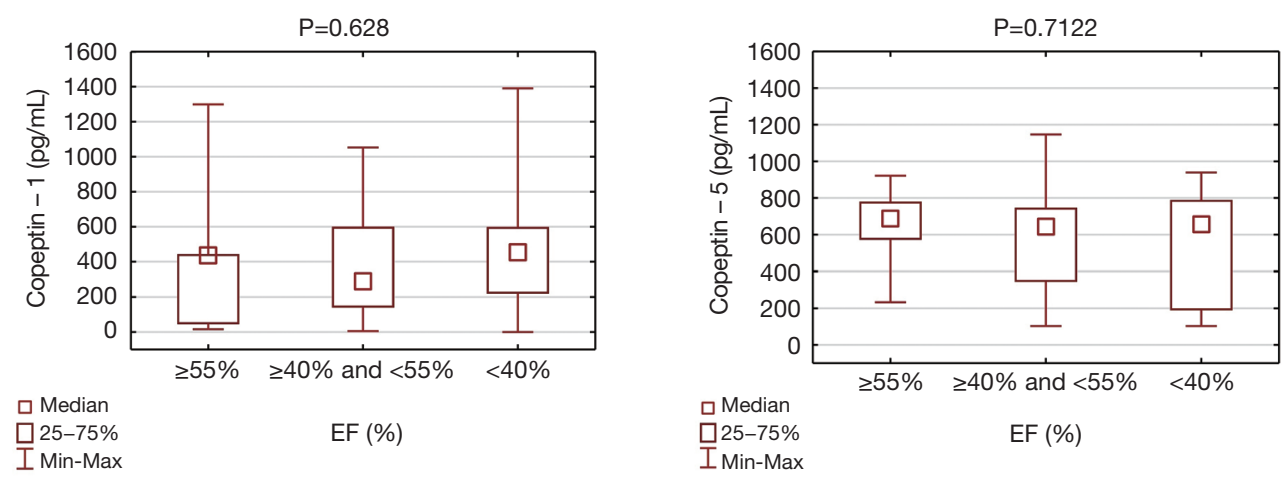

$\mathrm{EF}$, ejection fraction

Figure 3 Copeptin - 1 and copeptin - 2 concentration in patients with preserved (EF $\geq 55 \%$ ), moderately impaired (EF $\geq 40 \%$ and $\mathrm{EF}$ $<55 \%)$ and severly impaired ( $\mathrm{EF}<40 \%)$ left ventricular systolic function.

up period of 12 months, 24 subjects experienced MACE. Within 1 year $11 \%$ of patients died and $8 \%$ experienced reinfarction. Unscheduled coronary intervention was needed in $8 \%$ of patients and $1 \%$ required coronary bypass surgery.

We did not observe statistically significant difference in copeptin - 1 concentration between patients who developed MACE and uneventful subjects $(\mathrm{P}=0.0893)$. However, the difference in copeptin levels emerged as a predictor for the requirement of unplanned coronary revascularisation in ROC analysis. The calculated AUC was $0.639(95 \%$ CI: 0.504-0.773; $\mathrm{P}=0.0430)$. Patients whose copeptin concentration increased of $127.50 \mathrm{pg} / \mathrm{mL}$ or more during hospitalisation had almost fivefold higher risk of unplanned revascularisation procedures within one year after AMI [OR=4.93 (95\% CI: 0.58-41.70)].

Additionally, patients who developed MACE in the observational period had significantly higher copeptin - 2 levels. The evident difference was noted only for the composite endpoint $(\mathrm{P}=0.0445)$. In contrary, the analysis for each adverse cardiovascular event separately revealed no significant differences in copeptin concentration in patients who experienced reinfarction $(\mathrm{P}=0.7994)$, demanded unscheduled coronary procedure $(\mathrm{P}=0.2745)$ or died during the follow-up period $(\mathrm{P}=0.1110)$.

The prognostic accuracy of copeptin -2 levels was evaluated by ROC curves. We found an AUC of 0.637 (95\% CI: 0.504-0.769) for the incidence of MACE during follow-up ( $\mathrm{P}=0.0434)$. The cut-off value for copeptin -2 was calculated and was $686.4 \mathrm{pg} / \mathrm{mL}$ for which the OR of MACE was 2.70 (95\% CI: 1.048-6.965) (Figure 4).

Univariate logistic regression revealed that significant factors predicting MACE were age $(\mathrm{P}=0.0265)$, ejection fraction $(\mathrm{P}=0.0087)$, copeptin $-2(\mathrm{P}=0.0434)$, NTproBNP $-2(\mathrm{P}=0.0251)$ and GRACE score $(\mathrm{P}=0.0069)$. The analysis of the statistical significance between the differences in AUC was also performed. No significant differences were noted between AUC for copeptin and age, EF or NT-proBNP $(\mathrm{P}=0.9363, \mathrm{P}=0.7319$ and $\mathrm{P}=0.8566$, respectively).

In order to determine predictors for the occurrence of MACE after AMI multivariate analysis was performed. The following factors were included: age, GRACE score, EF, copeptin - 1, copeptin - 2, CRP - 1, CRP - 2, NT-proBNP -2 , creatinie, the presence of multi-vessel disease. The only statistically relevant predictors of MACE were concentration of copeptin $-2(\mathrm{P}=0.024)$ and ejection fraction $(\mathrm{P}=0.001)$ (Table 4). ROC curve for the achieved model is presented in Figure 5.

\section{Discussion}

This prospective cohort study extends previous findings in the prognostic value of copeptin in AMI patients. Firstly, we have noted that the difference in copeptin levels observed between $1^{\text {st }}$ and $4^{\text {th }} / 5^{\text {th }}$ day after AMI was useful in predicting the subsequent need for unscheduled coronary revascularisation procedure within 12 months. Secondly, copeptin concentration assessed on the $4^{\text {th }} / 5^{\text {th }}$ day of hospitalisation may be a predictor of composite endpoint in a 1 year follow-up.

\section{Changes in copeptin concentration}

Previous studies have reported that in patients with AMI copeptin concentration increases almost immediately after 


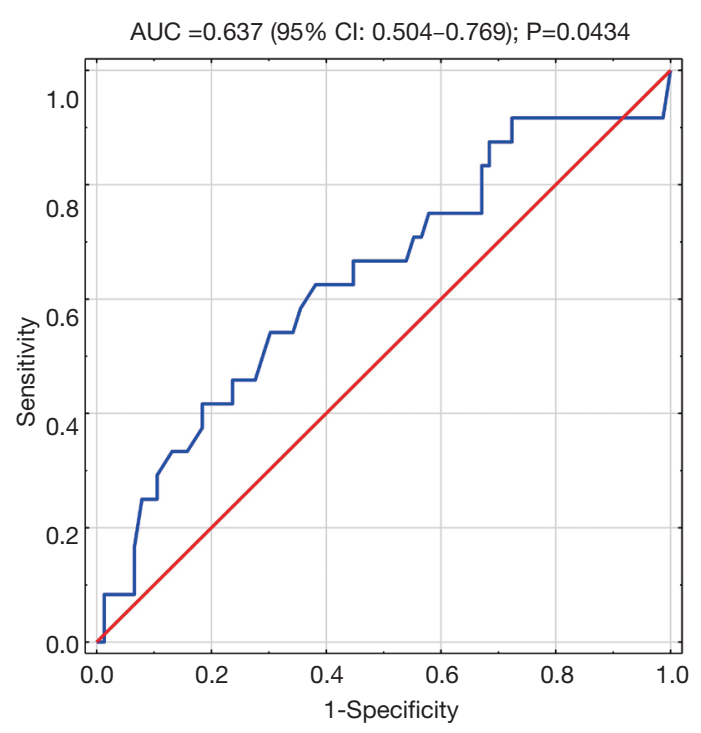

Figure 4 ROC-curve. Variable tested: copeptin concentration on $4^{\text {th }}-5^{\text {th }}$ day of hospitalisation in identifying patients at risk of MACE in the follow-up period.

Table 4 Predictors of MACE by multivariate analysis

\begin{tabular}{lccc}
\hline & Odds ratio & $95 \%$ confidence interval & $P$ \\
\hline Copeptin -2 & 1.002 & $1.000-1.005$ & 0.024 \\
EF (\%) & 0.887 & $0.825-0.953$ & 0.001 \\
\hline
\end{tabular}

$\mathrm{EF}$, ejection fraction; MACE, major adverse cardiovascular events.

symptoms onset and decreases gradually reaching the plateau phase on the $3^{\text {rd }}-5^{\text {th }}$ day (10-12). Myocardial ischemia acts as an endogenous stressor leading to rapid activation of neurohormonal system and increased copeptin release that is later reduced due to adaptive mechanisms (33). In our study different copeptin kinetics was noted. We observed significantly higher copeptin levels on the $4^{\text {th }} / 5^{\text {th }}$ day of hospitalisation. Copeptin being a biomarker of various types of endogenous stress may reflect the effect of various factors that occurred during hospitalisation. The difference in copeptin concentration between admission and following days of AMI showed a potential to predict unscheduled coronary revascularisation procedure in a 1 year followup. The increase of at least $127.50 \mathrm{pg} / \mathrm{mL}$ was associated with almost fivefold higher risk for unplanned coronary intervention during follow-up. To our best knowledge this is a novel observation, not reported previously in the literature.

The analysis of changes in copeptin levels after AMI was presented by Voors et al. (26) who assessed copeptin

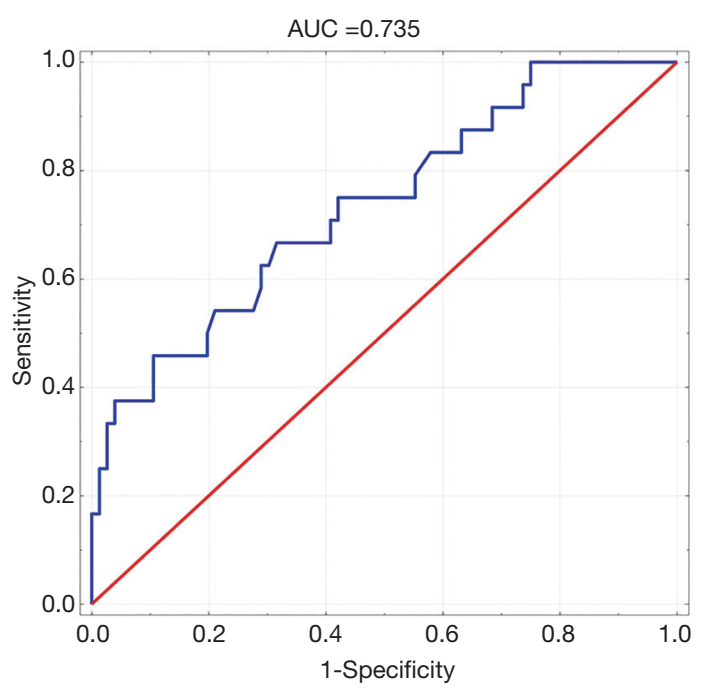

Figure 5 Receiver operating characteristics (ROC)-curve for the prognostic model achieved in a multivariate analysis in predicting major adverse cardiovascular events (MACE) incidence in a 1-year follow-up.

concentration at baseline (median 3 days after AMI), at 30 day and 1 year of follow-up. The highest concentration observed initially stabilized after 30 days. A percentual change in copeptin level between baseline and 1 month after AMI was significantly associated with a higher risk for all-cause death or the occurrence of composite cardiovascular endpoint (death, AMI, stroke and/or resuscitated cardiac arrest). In our study cohort, significantly higher copeptin concentration was noted in patients with final diagnosis of NSTEMI. The data available in the literature do not clearly indicate which type of myocardial infarction (STEMI or NSTEMI) is associated with greater copeptin secretion $(11,13,34)$. Although myocardial injury related to coronary artery total occlusion probably leads to higher copeptin release, NSTEMI patients in our cohort were high-risk patients with ongoing chest pain and dynamic ECG changes. Our findings are in line with the results presented by Afzali et al. (35).

\section{Copeptin and major adverse cardiovascular events}

The first study investigating the prognostic significance of copeptin was held by Khan et al. (10) in 980 patients after AMI with 780 STEMI patients, $67.8 \%$ of whom received thrombolytic therapy. Copeptin levels obtained on the $3^{\text {rd }}-5^{\text {th }}$ day of hospitalisation were significantly higher in patients who died or required admission to hospital due to congestive heart failure within 60 days after discharge. 
There was no relationship between copeptin concentration and the risk for reinfarction during follow-up. In LAMP II study (27), conducted among NSTEMI patients (17.4\% of whom was treated with PCI), copeptin concentration assessed in the early phase of AMI (the median time from the symptom onset to blood draw was 25 hours 45 minutes) remained the only predictive factor for death during 6 months after AMI in a multivariate analysis. Voors et al. (26) studied the prognostic value of copeptin (obtained at a mean of 3 days after AMI) in 224 patients with AMI and signs or symptoms of heart failure during mean followup of 33 months. Patients who remained in the highest quartile of copeptin baseline concentration had significantly increased mortality and higher incidence of the composite cardiovascular endpoint compared with other quartiles. A retrospective study of 149 patients with AMI (including 40 STEMI patients) treated with pPCI conducted by Choi et al. (36) revealed that copeptin concentration assessed immediately after PCI was significantly higher in subjects who experienced reinfarction, unscheduled coronary intervention or died during 30-month follow-up. Recently published study by Lattuca et al. (37) reported that in a cohort of 401 STEMI patients copeptin measured on admission was markedly higher in patients who died during the first 30-days and 12-months of follow-up than in survivors.

The analysis and comparison of studies on prognostic value of copeptin in patients after AMI is hindered by the differences between study groups and types of implemented therapy (thrombolysis or PCI) as well as different time points at which copeptin assays were performed. In our study we investigated prognostic accuracy of copeptin assessed both on admission and later during hospitalisation. In the light of the latest research with high-sensitivity cardiac troponins, copeptin as a diagnostic biomarker was only recommended when used with conventional $\mathrm{c} T$ n. However, its potential prognostic significance could justify additional laboratory analyzes. We have noted that copeptin concentration measured on the $4^{\text {th }} / 5^{\text {th }}$ day after AMI, but not on admission, has a potential to be an independent predictive factor for MACE. As a non-specific marker of endogenous stress it may reflect the effect of different factors that occur during hospitalisation. Concentration above $686.4 \mathrm{pg} / \mathrm{mL}$ was associated with nearly threefold higher incidence of a composite endpoint defined as allcause death, recurrent AMI or unscheduled coronary revascularisation considered together. These findings should, however, be considered preliminary and validation by multicentre studies performed on lager groups is definitely required. Confirmation that copeptin might give additional prognostic information to currently used tools may indicate patients who need more intensive treatment and post-hospital monitoring after first AMI.

\section{Study limitations}

The following limitations of our study should be considered. Firstly, we have enrolled a relatively small population and consequently we have observed a low number of events. That may limit the external validity of our study and hinder the generalisation of our findings. The results are therefore preliminary and require confirmation in lager multicenter studies but they might be helpful in defining the area for further research. Copeptin assessed during hospital stay may evidence of increased vasopressin system activity but also may reflect other unspecific endogenous stress factors, providing complex prognostic information. Studies focused on one type of myocardial infarction (STEMI or NSTEMI) could provide additional information in this topic. What is more, excluding patients with a history of AMI was related to relatively good results of the $\mathrm{LV}$ systolic function and therefore small impact of heart failure on a long-term outcome. Finally, obtaining follow-up data via telephone contact with patients or their relatives could have an impact on the quality of the information acquired.

\section{Conclusions}

The assessment of copeptin concentration in patients with AMI treated with PCI both on admission and on the $4^{\text {th }} / 5^{\text {th }}$ day of hospitalisation might have a prognostic value and could be an area for further studies.

\section{Acknowledgments}

Funding: This work was supported by Medical University of Lodz Grant for Young Researchers (grant number MRJ 502-14-189).

\section{Footnote}

Reporting Checklist: The authors have completed the STROBE reporting checklist. Available at https://dx.doi. org/10.21037/jtd-21-359

Data Sharing Statement: Available at https://dx.doi. 
org/10.21037/jtd-21-359

Peer Review File: Available at https://dx.doi.org/10.21037/ jtd-21-359

Conflicts of Interest: All authors have completed the ICMJE uniform disclosure form (available at https://dx.doi. org/10.21037/jtd-21-359). The authors have no conflicts of interest to declare.

Ethical Statement: The authors are accountable for all aspects of the work in ensuring that questions related to the accuracy or integrity of any part of the work are appropriately investigated and resolved. The study was conducted in accordance with the Declaration of Helsinki (as revised in 2013). The study was approved by Bioethics Committee at Medical University of Lodz (RNN/217/13/ $\mathrm{KE}$ ) and informed consent was taken from all individual participants.

Open Access Statement: This is an Open Access article distributed in accordance with the Creative Commons Attribution-NonCommercial-NoDerivs 4.0 International License (CC BY-NC-ND 4.0), which permits the noncommercial replication and distribution of the article with the strict proviso that no changes or edits are made and the original work is properly cited (including links to both the formal publication through the relevant DOI and the license). See: https://creativecommons.org/licenses/by-nc-nd/4.0/.

\section{References}

1. McAlpine HM, Morton JJ, Leckie B, et al. Neuroendocrine activation after acute myocardial infarction. Br Heart J 1988;60:117-24.

2. Laycock JF. editor. Perspectives on vasopressin. London: Imperial College Press, 2010.

3. Robertson GL, Mahr EA, Athar S, et al. Development and Clinical Application of a New Method for Radioimmunoassay of Arginine Vasopressin in Human Plasma. J Clin Invest 1973;52:2340-52.

4. Holwerda DA. A glycopeptide from the posteriori lobe of pig pituitaries. Eur J Biochem 1972;28:334-9.

5. Struck J, Morgenthaler NG, Bergmann A. Copeptin, a stable peptide derived from the vasopressin precursor, is elevated in serum of sepsis patients. Peptides 2005;26:2500-4.

6. Barat C, Simpson LR, Breslow E. Properties of Human Vasopressin Precursor Constructs: Inefficient Monomer
Folding in the Absence of Copeptin as a Potential Contributor to Diabetes Insipidus. Biochemistry 2004;43:8191-203.

7. Morgenthaler NG, Struck J, Alonso C, et al. Assay for measurement of Copeptin, a Stable Peptide Derived from the Precursor of Vasopressin. Clin Chem 2006;52:112-9.

8. Balanescu S, Kopp P, Gaskill MB, et al. Correlation of plasma copeptin and vasopressin concentrations in hypo-, iso-, and hyperosmolar states. J Clin Endocrinol Metab 2011;96:1046-52.

9. Heida JE, Boesten LSM, Ettema EM, et al. Comparison of ex vivo stability of copeptin and vasopressin. Clin Chem Lab Med 2017;55:984-92.

10. Khan SQ, Dhillon OS, O'Brien RJ, et al. C-terminal Provasopressin (Copeptin) as a novel and prognostic marker in acute myocardial infarction. Leicester Acute Myocardial Infarction Peptide (LAMP) Study. Circulation 2007;115:2103-10.

11. Reichlin T, Hochholzer W, Stelzig C, et al. Incremental value of copeptin for rapid rule out of acute myocardial infarction. J Am Coll Cardiol 2009;54:60-8.

12. Gu YL, Voors AA, Zijlstra F, et al. Comparison of the temporal release pattern of copeptin with conventional biomarkers in acute myocardial infarction. Clinical Research in Cardiology 2011;100:1069-76.

13. Maisel A, Mueller C, Neath SX, et al. Copeptin helps in the early detection of patients with acute myocardial infarction: primary results of the CHOPIN trial (Copeptin Helps in the early detection Of Patients with acute myocardial INfarction). J Am Coll Cardiol 2013;62:150-60.

14. Charpentier S, Maupas-Schwalm F, Cournot M, et al. Combination of copeptin and troponin assays to rapidly rule out non-ST elevation myocardial infarction in the emergency department. Acad Emerg Med 2012;19:517-24.

15. Chenevier-Gobeaux C, Freund Y, Claessens YE, et al. Copeptin for rapid rule out of acute myocardial infarction in emergency department. Int J Cardiol 2013;166:198-204.

16. Möckel M, Searle J, Hamm C, et al. Early discharge using single cardiac troponin and copeptin testing in patients with suspected acute coronary syndrome (ACS): a randomized, controlled clinical process study. Eur Heart J 2015;36:369-76.

17. Vargas KG, Kassem M, Mueller C, et al. Copeptin for the early rule-out of non-ST-elevation myocardial infarction. Int J Cardiol 2016;223:797-804.

18. Giannitsis E, Kehayova T, Vafaie M, et al. Combined Testing of High-Sensitivity Troponin T and Copeptin on Presentation at Prespecified Cutoffs Improves Rapid RuleOut of Non-ST-Segment Elevation Myocardial Infarction. 
Clin Chem 2011;57:1452-5.

19. Karakas M, Januzzi JL Jr, Meyer J, et al. Copeptin does not add diagnostic information to high-sensivity troponin in low- to intermediate-risk patients with acute chest pain: results from the rule out myocardial infarction by computed tomography (ROMICAT) study. Clin Chem 2011;57:1137-45.

20. Lipinski MJ, Escarcega RO, D’Ascenzo F. A systematic review and collaborative meta-analysis to determine the incremental value of copeptin for rapid rule-out of acute myocardial infarction. Am J Cardiol. 2014;113:1581-91.

21. Giannitsis E, Slagman A, Hamm ChW, et al. Copeptin combined with either non-high sensitivity or high sensitivity cardiac troponin for instant ruleout of suspected non-ST segment elevation myocardial infarction. Biomarkers 2020;25:649-58.

22. Mueller-Hennessen M, Lindahl B, Giannitsis E, et al. Combined testing of copeptin and high-sensitivity cardiac troponin $\mathrm{T}$ at presentation in comparison to other algorithms for rapid rule-out of acute myocardial infarction. Int J Cardiol 2019;276:261-7.

23. Kelly D, Squire IB, Khan SQ, et al. C-terminal provasopressin (copeptin) is associated with left ventricular dysfunction, remodeling, and clinical heart failure in survivors of myocardial infarction. J Card Fail 2008;14:739-45.

24. Reinstadler SJ, Klug G, Feistritzer HJ, et al. Association of copeptin with myocardial infarct size and myocardial function after ST segment elevation myocardial infarction. Heart 2013;99:1525-9.

25. Reinstadler SJ, Klug G, Feistritzer HJ, et al. Longterm predictive value of copeptin after acute myocardial infarction: a cardiac magnetic resonance study. Int J Cardiol. 2014;172:e359-60.

26. Voors AA, von Haeling S, Anker SD, et al. C-terminal provasopressin (copeptin) is a strong prognostic marker in patients with heart failure after an acute myocardial infarction: results from the OPTIMAAL study. Eur Heart J 2009;30:1187-94.

27. Narayan H, Dhillon OS, Quinn PA, et al. C-teminal provasopressin (copeptin) as a prognostic marker after acute non-ST-elevation myocardial infarction: Leicester Acute Myocardial Infarction Peptide II (LAMP II) study. Clin Sci (Lond) 2011;121:79-89.

28. Hernández-Romero D, García-Salas JM, López-Cuenca A, et al. High-Sensitivity troponin T and copeptin in nonST acute coronary syndromes: implications for prognosis and role of hs' $T$ T T and copeptin in non-STEACS. ScientificWorldJournal 2012;2012:578616.
29. Potocki M, Reichlin T, Thalmann S, et al. Diagnostic and prognostic impact of copeptin and high-sensitivity cardiac troponin $\mathrm{T}$ in patients with pre-existing coronary artery disease and suspected acute myocardial infarction. Heart 2012;98:558-65.

30. Sánchez M, Llorens $P$, Herrero P, et al. The utility of copeptin in the emergency department as a predictor of adverse outcomes in non-ST-elevation acute coronary syndrome: the COPED-PAO study. Emerg Med J 2014;31:286-91.

31. Ibanez B, James S, Agewall S, et al. 2017 ESC Guidelines for the management of acute myocardial infarction in patients presenting with ST-segment elevation. The Task Force for the management of acute myocardial infarction in patients presenting with ST-segment elevation of the European Society of Cardiology. Eur Heart J 2018;39:119-77.

32. Roffi M, Patrono C, Collet JP, et al. 2015 ESC Guidelines for the management of acute coronary syndromes in patients presenting without persistent ST-segment elevation: Task Force for the Management of Acute Coronary Syndromes in Patients Presenting without Persistent ST-Segment Elevation of the European Society of Cardiology. Eur Heart J 2016;37:267-315.

33. Liebetrau C, Nef H, Szardien S, et al. Release kinetics of copeptin in patients undergoing transcoronary ablation of septal hypertrophy. Clin Chem 2013;59:566-9.

34. Slagman A, Searle J, Müller C, et al. Temporal release pattern of copeptin and Troponin $\mathrm{T}$ in patients with suspected acute coronary syndrome and spontaneous acute myocardial infartcion. Clin Chem 2015;61:1273-82.

35. Afzali D, Erren M, Pavenstädt HJ, et al. Impact of copeptin on diagnosis, risk stratification, and intermediate-term prognosis of acute coronary syndromes. Clin Res Cardiol 2013;102:755-63.

36. Choi HJ, Kim MC, Sim DS, et al. Serum Copeptin Levels Predict Clinical Outcomes After Successful Percutaneous Coronary Intervention in Patients With Acute Myocardial Infarction. Ann Lab Med 2018;38:538-44.

37. Lattuca B, Sy V, Nguyen LS, et al. Copeptin as a prognostic biomarker in acute myocardial infarction. Int J Cardiol 2019;274:337-41.

Cite this article as: Roczek-Janowska M, Kacprzak M, Dzieciol M, Zielinska M, Chizynski K. Prognostic value of copeptin in patients with acute myocardial infarction treated with percutaneous coronary intervention: a prospective cohort study. J Thorac Dis 2021;13(7):4094-4103. doi: 10.21037/jtd-21-359 